\title{
CREATIVE INDUSTRIES AND MSME STRATEGIES THROUGH OPTIMIZING HUMAN RESOURCES IN UTILIZING DEMOGRAPHIC BONUSES BY USING THE TQM METHOD
}

\author{
Shinta Ratnawati ${ }^{1}$, Hanung Eka Atmaja ${ }^{{ }^{*}}$ \\ ${ }^{1}$ Universitas Tidar, Indonesia \\ *e-mail: hanung.ekaatmaja@untidar.ac.id
}

\begin{abstract}
Abstrak
Indonesia diprediksi akan mendapatkan bonus demografi pada tahun 2020-2030. Bonus demografi akan bermanfaat jika Indeks Pembangunan Manusia (IPM) Indonesia berkualitas tinggi. Di ASEAN, IPM Indonesia menempati urutan ke-6 dari 10 negara. Terkait fenomena tersebut, pemerintah gencar mendorong pelaku industri kreatif dan pelaku pembangunan menjadi agen pembangunan sebagai upaya memaksimalkan bonus demografi yang akan dihadapi Indonesia. Pemerintah menargetkan setidaknya tahun 2020 bisa mencetak 1.000 teknopreneur digital, 1 juta petani dan nelayan, serta 8 juta UKM go digital. Tujuan dari penelitian ini adalah untuk mengetahui gambaran umum, manfaat dan sejauh mana pengaruh SDM terhadap industri kreatif dan MSMEs. Total Quality Management merupakan pendekatan yang mencoba memaksimalkan daya saing organisasi melalui beberapa perbaikan: seperti peningkatan sumber daya manusia, kualitas produk, layanan, proses dan lingkungan. Hasil penelitian menunjukkan bahwa SDM berperan besar dalam meningkatkan kreativitas untuk menghasilkan produk sesuai permintaan pasar, optimalisasi pemanfaatan teknologi informasi dan komunikasi, serta meningkatkan industri kreatif dengan sesama industri kreatif serta perguruan tinggi.
\end{abstract}

Kata kunci: Industri Kreatif; MSME; Bonus Demografi; TQM

\begin{abstract}
Indonesia is predicted to get a demographic bonus in 2020-2030. A demographic bonus will be beneficial if Indonesia's Human Development Index (HDI) is high quality. In ASEAN, Indonesia's HDI ranks 6th out of 10 countries. The government is intensively pushing the creative industries and MSMEs to become agents of development to maximize the demographic bonus that Indonesia will face. The government is targeting at least 2020 to print 1,000 digital technopreneurs, one million farmers and fishers, and eight million SMEs going digital. The purpose of this study is to determine the general picture, the benefits, and the extent to which HR influences the creative industry and MSMEs. Total Quality Management is an approach that tries to maximize the competitiveness of organizations through several improvements: increasing human resources, the quality of products, services, processes, and the environment. The results of research with the application and implementation of the concept of Total Quality Management (TQM) in the creative industry and MSMEs that human resources have a significant role in increasing creativity to produce products according to market demand, optimizing the use of information and communication technology, and increasing creative industries with fellow creative industries as well as colleges.
\end{abstract}

Keywords: Creative Industries; MSME; Demographic Bonus; TQM

This is an open access article under the CC BY-SA license. Copyright @ 2021 by Author. Published by Universitas Pendidikan Ganesha.

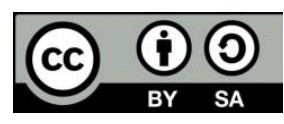


Shinta Ratnawati, Hanung Eka Atmaja | Creative Industries and MSME Strategies through Optimizing Human Resources in Utilizing Demographic Bonuses by Using the TQM Method

\section{PENDAHULUAN}

Jumlah penduduk Indonesia dari tahun ke tahun terus meningkat. Badan Perencanaan Pembangunan Nasional (Bappenas) memproyeksikan bahwa jumlah penduduk Indonesia pada tahun 2035 mendatang berjumlah 305,6 juta jiwa. Jumlah tahun 2020 sebesar 270,20 juta jiwa. Ini meningkat 3,2 juta jiwa dari total tahun 2019 yang sebesar 267 juta jiwa. Bonus demografi ini akan bermanfaat jika human development index (HDI) Indonesia berkualitas, tetapi faktanya human development index (HDI) Indonesia masih rendah yakni berada diurutan 111 dari 183 negara di dunia (UNDP, 2019). Terkait fenomena tersebut pemerintah sedang gencar untuk terus meningkatkan kesejahteraan Indonesia, yaitu dengan mendorong industri kreatif UMKM menjadi salah satu agent of development (Ratnawati,2018).

Menurut Resista (2016) industri kreatif merupakan salah satu pilar dalam membangun ekonomi nasional. Hal tersebut disebabkan karena industri kreatif mampu menciptakan sumber daya manusia yang berdaya saing di era globalisasi. Industri kreatif dipandang semakin penting dalam mendukung kesejahteraan dalam perekonomian, berbagai pihak berpendapat bahwa kreatif manusia adalah sumber daya ekonomi utama dan bahwa industri abad kedua puluh satu akan tergantung pada produksi, pengetahuan, kreativitas dan inovasi (Suyaman, 2015).

Berbicara industri kreatif tidak terlepas dari UMKM. Kegiatan Usaha Mikro Kecil dan Menengah (UMKM) merupakan salah satu bidang usaha yang dapat berkembang dan konsisten dalam perekonomian nasional. Berkembangnya Usaha Mikro Kecil dan Menengah (UMKM) dalam perekonomian Indonesia ditunjukkan oleh jumlah populasi penduduk sebagai pelaku usaha semakin meningkat, serta kontribusinya dalam penyerapan tenaga kerja, dan keanekaragaman produk yang dihasilkan domestik bruto (PDB), ekspor dan penciptaan modal tetap/investasi. Ditinjau secara sektoral, sebagian besar UMKM bergerak di sektor primer $(50,1 \%)$, dan sektor tersier $(42,5 \%)$, dan terkecil terdapat di sektor sekunder.

Table 1. Data Perkembangan Usaha Mikro Kecil dan Menengah (UMKM) 2019

\begin{tabular}{|c|c|c|c|c|}
\hline \multirow[b]{2}{*}{ NO } & \multirow[b]{2}{*}{ INDIKATOR } & \multirow[b]{2}{*}{ SATUAN } & \multicolumn{2}{|c|}{ TAHUN $2019^{* *}$} \\
\hline & & & JUMLAH & PANGSA (\%) \\
\hline 1 & 2 & 3 & 6 & 7 \\
\hline 1 & $\begin{array}{l}\text { UNIT USAHA (A+B) } \\
\text { A. Usaha Mikro, Kecil dan Menengah (UMKM) } \\
\text { - Usaha Mikro (UMi) } \\
\text { - Usaha Kecil (UK) } \\
\text { - Usaha Menengah(UM) } \\
\text { B. Usaha Besar (UB) }\end{array}$ & $\begin{array}{l}\text { (Unit) } \\
\text { (Unit) } \\
\text { (Unit) } \\
\text { (Unit) } \\
\text { (Unit) } \\
\text { (Unit) }\end{array}$ & $\begin{array}{r}65.471 .134 \\
65.465 .497 \\
64.601 .352 \\
798.679 \\
65.465 \\
5.637 \\
\end{array}$ & $\begin{array}{r}99,99 \\
98,67 \\
1,22 \\
0,10 \\
0,01\end{array}$ \\
\hline 2 & $\begin{array}{l}\text { TENAGA KERJA (A+B) } \\
\text { A. Usaha Mikro, Kecil dan Menengah (UMKM) } \\
\text { - Usaha Mikro (UMi) } \\
\text { - Usaha Kecil (UK) } \\
\text { - Usaha Menengah(UM) } \\
\text { B. Usaha Besar (UB) }\end{array}$ & $\begin{array}{l}\text { (Orang) } \\
\text { (Orang) } \\
\text { (Orang) } \\
\text { (Orang) } \\
\text { (Orang) } \\
\text { (Orang) }\end{array}$ & $\begin{array}{r}123.368 .672 \\
119.562 .843 \\
109.842 .384 \\
5.930 .317 \\
3.790 .142 \\
3.805 .829 \\
\end{array}$ & $\begin{array}{r}96,92 \\
89,04 \\
4,81 \\
3,07 \\
3,08 \\
\end{array}$ \\
\hline 3 & $\begin{array}{l}\text { PDB ATAS DASAR HARGA BERLAKU (A+B) } \\
\text { A. Usaha Mikro, Kecil dan Menengah (UMKM) } \\
\text { - Usaha Mikro (UMi) }\end{array}$ & $\begin{array}{r}\text { (Rp. Milyar) } \\
\text { (Rp. Milyar) } \\
\text { (Rp. Milyar) }\end{array}$ & $\begin{array}{r}15.832 .535,4 \\
9.580 .762,7 \\
5.913 .246,7\end{array}$ & $\begin{array}{l}60,51 \\
37,35\end{array}$ \\
\hline
\end{tabular}


Shinta Ratnawati, Hanung Eka Atmaja | Creative Industries and MSME Strategies through Optimizing Human Resources in Utilizing Demographic Bonuses by Using the TQM Method

\begin{tabular}{|c|c|c|c|c|}
\hline & $\begin{array}{l}\text { - Usaha Kecil (UK) } \\
\text { - Usaha Menengah(UM) } \\
\text { B. Usaha Besar (UB) }\end{array}$ & $\begin{array}{l}\text { (Rp. Milyar) } \\
\text { (Rp. Milyar) } \\
\text { (Rp. Milyar) }\end{array}$ & $\begin{array}{l}1.508 .970,1 \\
2.158 .545,8 \\
6.251 .772,7 \\
\end{array}$ & $\begin{array}{r}9,53 \\
13,63 \\
39,49 \\
\end{array}$ \\
\hline 4 & $\begin{array}{l}\text { PDB ATAS DASAR HARGA KONSTAN } 2000 \\
\text { (A+B) } \\
\text { A. Usaha Mikro, Kecil dan Menengah (UMKM) } \\
\text { - Usaha Mikro (UMi) } \\
\text { - Usaha Kecil (UK) } \\
\text { - Usaha Menengah(UM) } \\
\text { B. Usaha Besar (UB) }\end{array}$ & $\begin{array}{l}\text { (Rp. Milyar) } \\
\text { (Rp. Milyar) } \\
\text { (Rp. Milyar) } \\
\text { (Rp. Milyar) } \\
\text { (Rp. Milyar) } \\
\text { (Rp. Milyar) } \\
\end{array}$ & \begin{tabular}{|l|}
$12.309 .904,8$ \\
$7.034 .146,7$ \\
$3.701 .368,0$ \\
$1.536 .961,1$ \\
$1.795 .817,7$ \\
$5.275 .758,1$ \\
\end{tabular} & $\begin{array}{l}\mathbf{5 7 , 1 4} \\
30,07 \\
12,49 \\
14,59 \\
\mathbf{4 2 , 8 6} \\
\end{array}$ \\
\hline 5 & $\begin{array}{l}\text { TOTAL EKSPOR NON MIGAS (A+B) } \\
\text { A. Usaha Mikro, Kecil dan Menengah (UMKM) } \\
\text { - Usaha Mikro (UMi) } \\
\text { - Usaha Kecil (UK) } \\
\text { - Usaha Menengah(UM) } \\
\text { B. Usaha Besar (UB) }\end{array}$ & $\begin{array}{l}\text { (Rp. Milyar) } \\
\text { (Rp. Milyar) } \\
\text { (Rp. Milyar) } \\
\text { (Rp. Milyar) } \\
\text { (Rp. Milyar) } \\
\text { (Rp. Milyar) }\end{array}$ & $\begin{array}{r}2.167 .079,7 \\
339.190,5 \\
30.289,7 \\
56.407,4 \\
252.493,4 \\
1.827 .889,2 \\
\end{array}$ & $\begin{array}{r}15,65 \\
1,40 \\
2,60 \\
11,65 \\
84,35 \\
\end{array}$ \\
\hline 6 & 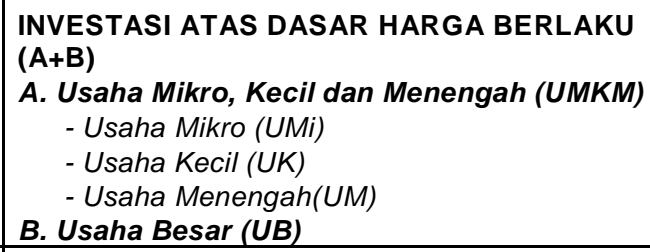 & $\begin{array}{l}\text { (Rp. Milyar) } \\
\text { (Rp. Milyar) } \\
\text { (Rp. Milyar) } \\
\text { (Rp. Milyar) } \\
\text { (Rp. Milyar) } \\
\text { (Rp. Milyar) }\end{array}$ & $\begin{array}{r}4.363 .262,0 \\
2.619 .382,0 \\
294.418,5 \\
1.018 .939,6 \\
1.306 .023,9 \\
1.743 .880,0 \\
\end{array}$ & $\begin{array}{r}60,03 \\
6,75 \\
23,35 \\
29,93 \\
39,97 \\
\end{array}$ \\
\hline 7 & $\begin{array}{l}\text { INVESTASI ATAS DASAR HARGA KONSTAN } \\
2000 \text { (A+B) } \\
\text { A. Usaha Mikro, Kecil dan Menengah (UMKM) } \\
\text { - Usaha Mikro (UMi) } \\
\text { - Usaha Kecil (UK) } \\
\text { - Usaha Menengah(UM) } \\
\text { B. Usaha Besar (UB) }\end{array}$ & $\begin{array}{l}\text { (Rp. Milyar) } \\
\text { (Rp. Milyar) } \\
\text { (Rp. Milyar) } \\
\text { (Rp. Milyar) } \\
\text { (Rp. Milyar) } \\
\text { (Rp. Milyar) }\end{array}$ & \begin{tabular}{r|}
$3.166 .958,0$ \\
$1.716 .750,0$ \\
$218.370,6$ \\
$537.686,1$ \\
$960.693,3$ \\
$1.450 .208,0$ \\
\end{tabular} & $\begin{array}{r}54,21 \\
6,90 \\
16,98 \\
30,33 \\
45,79 \\
\end{array}$ \\
\hline
\end{tabular}

70
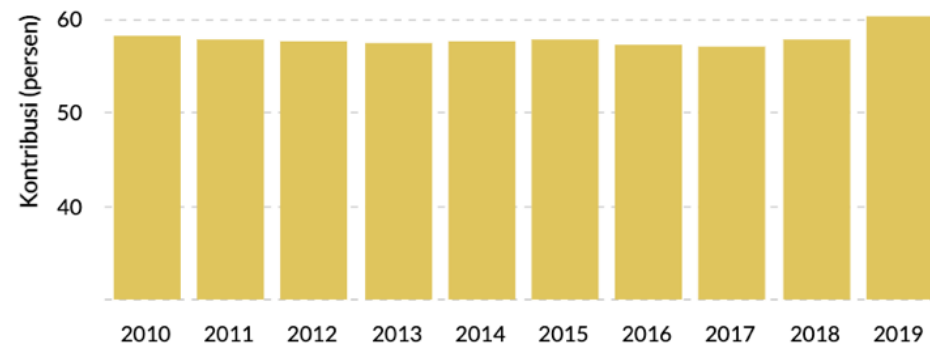

Tahun

Gambar 1. Kontribusi Usaha Mikro Kecil dan Menengah (UMKM) 2010-2019.

(Sumber : Kementerian Koperasi dan Usaha Kecil dan Menengah) 
Pada gambar 1, kegiatan Usaha Mikro Kecil dan Menengah mampu memberikan kontribusi terhadap total $60 \%$ dari total Pendapatan Domestik Bruto (PDB) sebesar Rp. 2.394,5 triliun pada tahun 2019. Lebih lanjut seperti yang terlihat pada tabel 1. UMKM mampu menyerap $97 \%$ dari total tenaga kerja nasional, dengan rincian usaha mikro sebanyak $89,2 \%$, usaha kecil sebanyak $4,47 \%$, usaha menengah $3,37 \%$ dan usaha besar sebanyak 3\%. Namun bila ditinjau kembali produktivitas UMKM masih tergolong rendah, hal tersebut menjadi kendala bagi UMKM untuk terus mengembangkan diri. Terlepas dari produktivitas yang rendah,

UMKM memiliki daya tahan dan fleksibilitas sebagai sumber utama penghidupan. Meskipun memiliki daya tahan terhadap guncangan ekonomi, belum dapat dipastikan bahwa UMKM akan mampu bertahan dalam kondisi tersebut bila tidak didukung dengan SDM yang baik dalam pengolahannya. Sumber daya manusia menjadi sangat vital dalam dunia usaha, sebab tanpa SDM yang berkualitas dalam suatu perusahaan baik berskala kecil maupun besar perusahaan tersebut tidak akan mampu memaksimalkan jalannya roda industri. Untuk menjawab permasalahan SDM yang terdapat pada UMKM perlu dibuatlah sebuah metode yang mampu memperbaiki sistem manajemen. TQM (Total Quality Manajemen) menjadi salah satu metode yang dibutuhkan dalam memperbaiki sistem manajemen.

\section{METODE}

Jenis penelitian yang dilakukan adalah penelitian deskriptif dengan menggunakan studi literatur sehingga dalam penelitiannya tidak merumuskan hipotesa namun menemukan hipotesis. Penelitian ini akan menganalisis hasil tentang analisis SWOT pada UMKM di Indonesia. Sedangkan teknik pengumpulan data sebagai bahan pendukung penelitian adalah melalui dokumentasi.

Data yang dibutuhkan dalam penelitian ini adalah data sekunder yang merupakan data penelitian yang diperoleh dari sumber kedua atau sumber sekunder dari data yang kita butuhkan (Bungin, 2010). Sumber data sekunder dapat berupa hasil pengolahan lebih lanjut dari data primer yang disajikan dalam bentuk lain atau dari orang lain (Sugiyono., 2008).

Pada penelitian ini data sekunder digunakan untuk menemukan indikatorindikator yang akan dianalisis menggunakan metode SWOT, mengetahui data statistik UMKM, penyerapan tenaga kerja yang bersumber dari Kementerian Koperasi dan UMKM, serta pengaruh kualitas SDM pada industri kreatif dan UMKM terhadap PDB.

Dalam penelitian ini metode yang digunakan adalah kuantitatif dengan format deskriptif bertujuan untuk menjelaskan, meringkaskan berbagai kondisi, berbagai situasi, atau beberapa variabel yang menjadi objek penelitian berdasarkan apa yang terjadi, kemudian mengangkat kepermukaan gambaran tentang kondisi (Bungin, 2010).

Upaya perumusan strategi optimalisasi SDM dalam pemanfaatan bonus demografi pada industri kreatif UMKM maka digunakan metode TQM (Total Quality Management) dengan menggunakan alisis SWOT (Strength, Weakness, Oportunity, Threat). Analisis SWOT digunakan untuk mengetahui strategi apa yang akan digunakan setelah melihat kekuatan, kelemahan, peluang, serta ancaman yang dihadapi oleh suatu industri (UMKM).

\section{HASIL DAN PEMBAHASAN \\ Pentingnya Industri Kreatif UMKM di Indonesia}

UMKM berkontribusi besar terhadap perekonomian Indonesia. Pada tahun 2014, Abdul Kadir Damanik selaku Staf Ahli Menteri KUKM bidang Penerapan Nilai Dasar Koperasi menyebutkan terdapat sekitar 57,9 juta pelaku UMKM di Indonesia dan jumlahnya terus meningkat. UMKM telah memberikan kontribusi pada PBD $58,92 \%$ dan penyerapan tenaga kerja $97,30 \%$. Menurut keputusan Presiden RI no. 99 tahun 1998 pengertian usaha kecil adalah "Kegiatan ekonomi rakyat yang berskala kecil dengan bidang usaha yang secara mayoritas merupakan kegiatan usaha kecil yang perlu dilindungi untuk mencegah dari persaingan usaha yang tidak sehat". Usaha kecil sangatlah dekat dengan 
masyarakat menengah ke bawah. Tidak sedikit masyarakat yang memulai usahanya dan menjadikannya sebagai sumber pendapatan keluarga. Meskipun UMKM unbankable, namun kontribusi UMKM cukup feasible. UMKM merupakan sebuah kegiatan perekonomian yang tidak eksklusif dan partisipatif sehingga bisa dilaksanakan oleh siapa saja.

Sampai saat ini, UMKM telah menjadi tulang punggung perekonomian Indonesia. Presiden Jokowi memaparkan bahwa UMKM menyumbangkan angka 88,38-99,9\% dalam bentuk usaha di ASEAN dengan penyerapan tenaga kerja mencapai 51,7$97,2 \%$ dan menyerap lebih dari $97 \%$ tenaga kerja domestik. UMKM juga sering dikaitkan dengan pengentasan masalah-masalah ekonomi dan sosial, seperti tingginya tingkat kemiskinan, besarnya jumlah pengangguran, ketimpangan distribusi pendapatan, maupun proses pembangunan yang tidak merata. Keberhasilan UMKM yang merupakan kelompok usaha yang memiliki jumlah paling besar dan cukup dominan dalam perekonomian, akan sangat mempengaruhi pencapaian kesuksesan dalam mewujudkan SDG's. Dalam mewujudkan tujuan-tujuan SDG's di Dunia dan Indonesia pada khususnya maka diperlukan penekanan baru pada pengembangan dan pemajuan UMKM serta mempersiapkan strategi program yang lebih terstruktur untuk semakin meningkatkan daya saing dan daya tahan UMKM. Kemampuan perencanaan strategis yang buruk, singkatnya terminisme, kurangnya fokus pada masalah eksternal dan strategis adalah area utama yang membatasi keberhasilan UMKM seperti yang ditunjukkan dalam penelitian HudsonSmith\&Smith,2007;Hudson, Smart, \& Bourne, 2001.

\section{Penerapan dan Implementasi TQM dalam Industri Kreatif UMKM}

Sesuai pilar utama MEA ini, akan tercipta pasar tunggal di wilayah ASEAN. Pasar yang akan memunculkan aliran perdagangan barang, jasa, modal dan investasi secara bebas. Indonesia sebagai anggota ASEAN yang mempunyai jumlah penduduk paling banyak akan sangat berpotensi menjadi pasar yang kuat untuk perdagangan barang dan jasa yang dihasilkan oleh negara-negara di ASEAN. Dalam penerapan TQM pada UMKM di Indonesia masih dilakukan dalam bentuk sederhana, pemeriksaan lebih ditekankan pada pengamatan visual secara kualitatif. Perencanaan mutu dilakukan untuk mengetahui kebutuhan dan persyaratan konsumen dengan melakukan wawancara langsung dengan konsumen, melihat contoh model di mall dan melihat produk dari buku atau majalah. Merancang proses dan peralatan pembuatan produk dengan melakukan kunjungan dan observasi ke industri produk yang lebih besar (benchmarking) tetapi belum membuat prosedur tertulis.

Meskipun selama ini penerapan TQM pada perusahaan atau organisasi lebih menekankan pada kualitas output dan konsumen bukan kuantitas produksi ataupun jumlah tenaga kerja yang mampu diserap oleh perusahaan atau organisasi, namun tanpa disadari bahwa permasalahan utama dalam UMKM adalah pengembangan Sumber Daya Manusia dalam berbagai aspek terutama di bidang kompetensi seperti knowledge, skill dan ability serta attitude dalam berwirausaha. Seiring dengan adanya bonus demografi yang akan terjadi pada tahun 2030, maka fokus dari penerapan TQM harus diperlebar mencakup pengembangan SDM sehingga bonus demografi tidak menjadi boomerang terhadap negara dan SDM yang ada berkompeten sebagai motor penggerak UMKM. Dalam pasar global yang berubah secara terus menerus komponen pengembangan SDM dalam ekonomi kreatif harus mengerti tentang konsep dan falsafah sistem manajemen yang menjadi mentalitas dasar supaya bisa mengikuti perubahan orientasi pasar selain upaya peningkatan mutu.

\section{Analisis TQM Terhadap Optimalisasi SDM dalam Pemanfaatan Bonus Demografi Pada Industri Kreatif UMKM \\ Dari hasil analisa penelitian} tentang Industri Kreatif UMKM terhadap optimalisasi pemanfaatan bonus demografi yang dapat dilihat dari 
gambaran umum UMKM mulai dari penyerapan tenaga kerja, kontribusi UMKM terhadap PDB Nasional.
Beberapa faktor internal (IFE) dan eksternal (EFE) dapat diidentifikasikan seperti terlihat pada Tabel 2 .

Tabel 2. Analisis TQM terhadap Optimalisasi SDM

\begin{tabular}{|c|c|c|c|}
\hline No & Faktor & Aspek & Keterangan \\
\hline \multirow[t]{2}{*}{1} & \multirow[t]{2}{*}{$\begin{array}{l}\text { Internal } \\
\text { (IFE) }\end{array}$} & Kekuatan & $\begin{array}{l}\text { 1) Sumber daya manusia yang melimpah. Indonesia yang } \\
\text { menempati urutan ke-4 sebagai negara berpenduduk terbanyak } \\
\text { menjadi salah satu kekuatan untuk memanfaatkan UMKM } \\
\text { sebagai salah satu alat untuk meningkatkan pertumbuhan } \\
\text { ekonomi dan dapat membuka lapangan pekerjaan sehingga } \\
\text { mengurangi jumlah pengangguran. } \\
\text { 2) Daya tahan terhadap goncangan ekonomi karena mampu mampu } \\
\text { mempertahankan kelangsungan usahanya demi untuk } \\
\text { mendapatan pendapatan untuk menopang kehidupan. } \\
\text { 3) Fleksibilitas Operasional. } \\
\text { 4) Kecepatan Inovasi. } \\
\text { 5) Struktur biaya rendah. } \\
\text { 6) Kemampuan fokus disektor spesifik. }\end{array}$ \\
\hline & & Kelemahan & $\begin{array}{l}\text { 1) Kualitas SDM yang kurang berkualitas. } \\
\text { 2) Lemahnya akses ke pemerintah dan lembaga keuangan. Hal } \\
\text { tersebut dikarenakan banyak dari UMKM belum berbadan hukum. } \\
\text { 3) Pengetahuan yang minim akan manajemen bisnis. Manajemen } \\
\text { bisnis UMKM adalah manajemen yang sederhana. Pengetahuan } \\
\text { yang minim tentang manajemen bisnis menjadikan persoalan } \\
\text { pengelolaan keuangan, admnistrasi, dan penyusunan rencana } \\
\text { usaha tidak diketahui secara formal. Hanya berdasarkan } \\
\text { pengalaman sederhana yang dimiliki. } \\
\text { 4) Penyediaan bahan baku yang murah dan kontinyu. UMKM harus } \\
\text { memiliki sumber bahan baku yang murah dan kontinyu, agar } \\
\text { usaha dapat tetap berjalan. Tetapi keterbatasan yang dimiliki } \\
\text { UMKM, baik lemahnya akses ke lembaga keuangan } \\
\text { ataupemerintah menjadikan UMKM sering kali kesulitan ketika } \\
\text { harga bahan baku tidak stabil. } \\
\text { 5) Kurang dikuasainya sering diidentikan dengan teknologi } \\
\text { sederhana. Tetapi dengan berkembangnya usaha serta } \\
\text { perkembangan teknologi yang ada akhirnya menuntut UMKM } \\
\text { menggunakan teknologi yang tidak sederhana. Permasalahan } \\
\text { yang dihadapi dalam penguasaan teknologi baru adalah kualitas } \\
\text { SDM yang kurang mampu menangani teknologi baru secara baik. } \\
\text { 6) Belum konsistennya kebijakan setiap unit kerja dalam } \\
\text { mendukung upaya-upaya mewujudkan pelaksanaan koordinasi } \\
\text { perencanaan dan penyusunan kebijakan, sinkronisasi } \\
\text { pelaksanaan kebijakan di bidang pelaksanaan dan } \\
\text { penanggulangan ancaman. } \\
\text { 7) Kontrol yang lemah dalam anggaran dan pembiayaan }\end{array}$ \\
\hline \multirow[t]{2}{*}{2} & \multirow[t]{2}{*}{$\begin{array}{l}\text { Eksternal } \\
\text { (EFE) }\end{array}$} & Peluang & $\begin{array}{l}\text { 1) Menyerap banyak tenaga kerja. } \\
\text { 2) Menigkatkan daya kreatif. } \\
\text { 3) Adanya MEA (Masyarakat Ekonomi Asean). } \\
\text { 4) Masyarakat yang semakin komsumtif. } \\
\text { 5) Semakin meningkatnya upaya pemberantasan pengangguran. } \\
\text { 6) Semakin intensifnya upaya pemberantasan kemiskinan dan } \\
\text { kualitas SDM yang rendah, serta kontrol sosial yang semakin } \\
\text { kuat di masyarakat kalangan ekonomi menengah ke bawah. }\end{array}$ \\
\hline & & Ancaman & $\begin{array}{l}\text { 1) Banyaknya produk impor, hal tersebut disebabkan masyarakat } \\
\text { Indonesia yang lebih menyukai produk impor daripada produk } \\
\text { lokal. } \\
\text { 2) Lemahnya sistem dan kelembagaan sosial yang menaungi } \\
\text { UMKM dalam memelihara dan melindungi UMKM. } \\
\text { 3) Besarnya kompleksitas masalah internal dan atau eksternal } \\
\text { UKM. }\end{array}$ \\
\hline
\end{tabular}


Shinta Ratnawati, Hanung Eka Atmaja | Creative Industries and MSME Strategies through Optimizing Human Resources in Utilizing Demographic Bonuses by Using the TQM Method

\begin{tabular}{|l|l|l|}
\hline & 4) $\begin{array}{l}\text { Tumpang tindihnya kegiatan peningkatan kesejahteraan rakyat } \\
\text { dan penanggulangan kemiskinan oleh berbagai }\end{array}$ \\
& instansi/perusahaan teknis. \\
& 5) $\begin{array}{l}\text { Kebijakan pemerintah yang belum sepenuhnya memberikan iklim } \\
\text { kondusif terhadap UMKM. }\end{array}$ \\
& 6) Kualitas SDM yang kurang berkualitas akan menjadi beban bagi \\
& negara di tahun mendatang. \\
\hline
\end{tabular}

\section{Memformulasikan menggunakan ANALISIS SWOT}

Data SWOT kualitatif di atas dapat dikembangkan secara kuantitaif melalui perhitungan Analisis SWOT yang dikembangkan oleh (Pearce \& Robinson, 2007) agar diketahui secara pasti posisi organisasi yang sesungguhnya.

Table 3. Hasil Perhitungan Matriks IFE

\begin{tabular}{|c|c|c|c|c|}
\hline No & Faktor Internal & Bobot & Rating & Skor \\
\hline & Kekuatan & (a) & (b) & (c) \\
\hline 1 & Sumber daya manusia yang melimpah. (S1). & 0,15 & 5 & 0,75 \\
\hline 2 & Fleksibilitas operasional (S2). & 0,055 & 3 & 0,165 \\
\hline 3 & Kecepatan inovasi (S3) & 0,075 & 4 & 0,3 \\
\hline 4 & Struktur biaya rendah (S4). & 0,055 & 3 & 0,165 \\
\hline 5 & Kemampuan fokus di sektor spesifik (S5). & 0,045 & 3 & 0,135 \\
\hline 6 & Daya tahan terhadap goncangan ekonomi (S6). & 0,1 & 4 & 0,4 \\
\hline & Jumlah Kekuatan & 0,48 & & 1,915 \\
\hline & Kelemahan & & & \\
\hline 1 & $\begin{array}{l}\text { Kualitas SDM yang kurang berkualitas atau } \\
\text { kurangnya tenaga ahli (W1). }\end{array}$ & 0,12 & 5 & 0,6 \\
\hline 2 & $\begin{array}{l}\text { Lemahnya akses ke pemerintah dan lembaga } \\
\text { keuangan. Hal tersebut dikarenakan banyak dari } \\
\text { UMKM belum berbadan hukum (W2). }\end{array}$ & 0,085 & 4 & 0,34 \\
\hline 3 & $\begin{array}{l}\text { Pengetahuan yang minim akan manajemen } \\
\text { bisnis (W3). }\end{array}$ & 0,075 & 4 & 0,3 \\
\hline 4 & $\begin{array}{l}\text { Penyediaan bahan baku yang murah dan } \\
\text { kontinyu (W4). }\end{array}$ & 0,045 & 3 & 0,135 \\
\hline 5 & Kurang dikuasainya teknologi baru (W5). & 0,065 & 3 & 0,195 \\
\hline 6 & $\begin{array}{l}\text { Belum konsistennya kebijakan setiap unit kerja } \\
\text { dalam mendukung upaya-upaya mewujudkan } \\
\text { pelaksanaan koordinasi perencanaan dan } \\
\text { penyusunan kebijakan (W6). }\end{array}$ & 0,065 & 3 & 0,195 \\
\hline 7 & $\begin{array}{l}\text { Kontrol yang lemah dalam anggaran dan } \\
\text { pembiayaan (W7). }\end{array}$ & 0,065 & 3 & 0,195 \\
\hline & Jumlah Kelemahan & 0,52 & & 1,96 \\
\hline & Total & 1,00 & & 3,875 \\
\hline
\end{tabular}

Hasil analisis matriks IFE pada UMKM didapatkan skor total sebesar 3,875

Tabel 4. Hasil Perhitungan Matriks EFE

\begin{tabular}{|c|c|c|c|c|}
\hline No. & Faktor Internal & Bobot & Rating & Skor \\
\hline & Peluang & (a) & (b) & (c) \\
\hline 1 & Menyerap banyak tenaga kerja (O1). & 0,15 & 5 & 0,75 \\
\hline 2 & Meningkatkan daya kreatif (O2). & 0,065 & 3 & 0,195 \\
\hline 3 & Adanya MEA (O3). & 0,035 & 2 & 0,07 \\
\hline 4 & Masyarakat yang semakin konsumtif (O4). & 0,045 & 3 & 0,135 \\
\hline 5 & $\begin{array}{l}\text { Semakin meningkatnya upaya pemberantasan } \\
\text { pengangguran (O5). }\end{array}$ & 0,15 & 5 & 0,75 \\
\hline
\end{tabular}


Shinta Ratnawati, Hanung Eka Atmaja | Creative Industries and MSME Strategies through Optimizing Human Resources in Utilizing Demographic Bonuses by Using the TQM Method

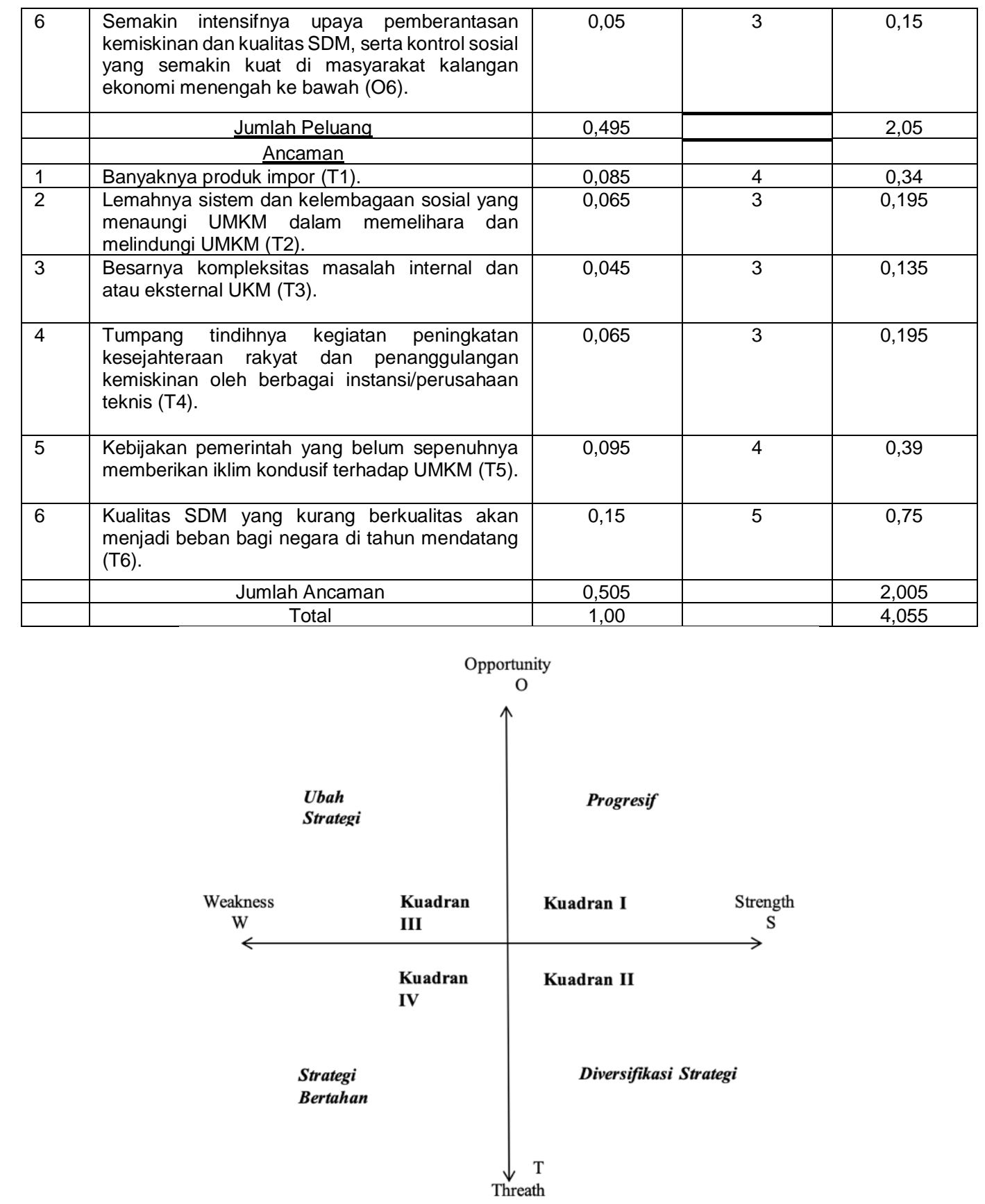

Gambar 2.

Grafik Analisis SWOT

Angka hasil analisis SWOT menunjukkan bahwa UMKM mempunyai respon yang sangat baik terhadap peluang yang ada dan menghindari ancaman yang muncul. Sehingga tabel EFE posisi UMKM berada pada kuadran I, yang berarti posisi ini menandakan bahwa peluang dan kekuatan menjadi point yang harus ditumbuhkembangjan dalam situasi saat ini. Rekomendasi strategi yang diberikan adalah strategi progresif harus dilakukan, artinya organisasi dalam kondisi prima dan mantap sehingga sangat dimungkinkan untuk terus melakukan ekspansi, memperbesar pertumbuhan dan meraih kemajuan secara maksima 


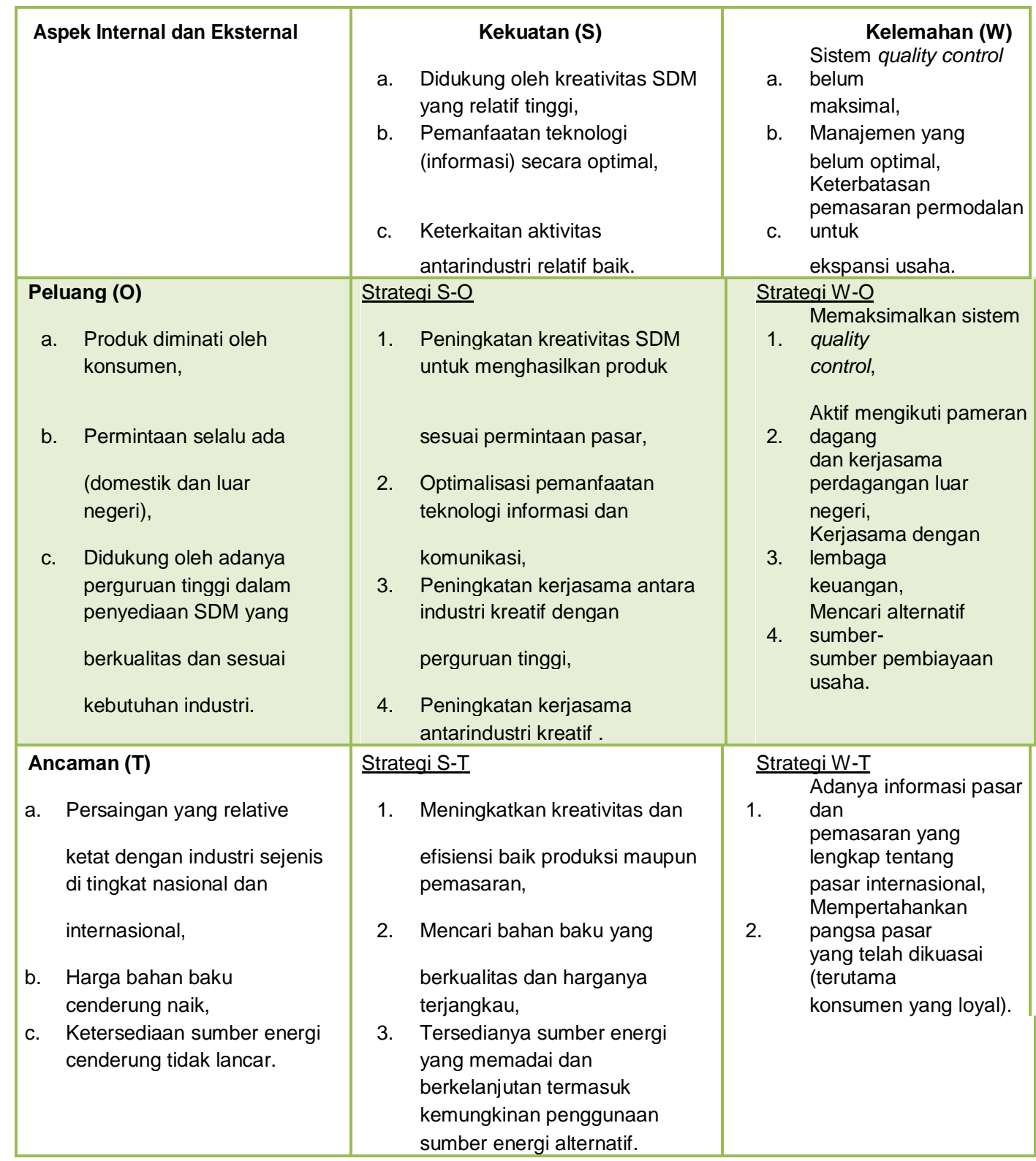

SIMPULAN DAN SARAN

Strategi industri kreatif dan umkm melalui optimalisasi SDM dalam pemanfaatan bonus demografi dengan menggunakan Metode TQM, sesuai dengan hasil analisis SWOT harus melakukan beberapa hal yang menjadi poin penting sebagai berikut. Strategi S-O meliputi peningkatan kreativitas SDM untuk menghasilkan produk sesuai permintaan 
pasar, optimalisasi pemanfaatan teknologi informasi dan komunikasi, peningkatan kerjasama anara industri kreatif dengan pergiruan tinggi dan peningkatan kerjasama antara industri kreatif. Strategi W-O meliputi memaksimalkan sistem Quality Control, aktif mengikuti pameran dagang dan kerjasama perdagangan luar negeri, kerjasama dengan Lembaga keuangan dan mencari alternatif sumber-sumber pembiayaan usaha. Strategi S_T mencakup meningkatkan kreativitas dan efisiensi baik produksi maupun pemasaran, mencari bahan baku yang berkualitas dan harganya terjangkau dan tersedianya sumber energi yang memadai dan berkelanjutan termasuk kemungkinan penggunaan sumber alternative. Strategi W-T mencakup adanya informasi pasar dan pemasaran yang lengakap tentang pasar internasional dan mempertahankan pangsa pasar yang telah dikuasai (terutama konsumen yang loyal)

Perolehan keunggulan kompetitif dan memastikan membangun keberlanjutan UMKM, dengan mencapai kinerja operasional, memuaskan pelanggan dan secara subtansial meningkatkan kualitas produknya. Dipengaruhi oleh elemen TQM. Namun disatu sisi TQM hanyalah satu alat untuk meningkatkan kualitas. Penggunaan kualitas saja tidak dapat menjamin perkembangan kualitas secara berkelanjutan tanpa bimbingan yang tepat dari manajemen, partisipasi karyawan dan dukungan pemasok.

Penelitian ini mempunyai batasan, data adalah bukti subjektif dari data dan pengamatan secara makro, sebuah fakta yang dapat menyebabkan bias. Untuk penelitian masa depan secara khusus validitas bisa didapatnya dengan objek penelitian yang scopenya lebih mikro yang dapat menyebabkan bias. Untuk penelitian masa depan secara khusus validitas bisa didapatnya dengan objek penelitian yang scopenya lebih mikro.
DAFTAR PUSTAKA

Anggraini, N. (2008). "Industri Kreatif. Jurnal Ekonomi Desember, 13(3), 144-151.

Brah, S., \& Lim, H. (2006). The effects of technology and TQM on the performance of logistics companies. International Journal of Physical Distribution \& Logistics Management, 36(3), 192-209.

Bungin, B. (2010). Metodologi Penelitian Kualitatif: Komunikasi, Ekonomi, dan Kebijakan Publik serta IImu Sosial lainnya. Jakarta: Kencana Prenada Media.

Cemal, Z., \& Sadikoglu, E. (2009). The relationship between total quality management (TQM) practices and organizational performance: An empirical investigation. International Journal of Production Economics, 11(3), 140-156.

Demirbag, M., Tatoglu, E., Tekinkus, M. And Zaim, S. (2006). An analysis of the relationship between TQM implementation and organizational performance: evidence from Turkish smes. Journal of Manufacturing Technology Management, 17(6), 829847.

Gaspersz, V. (2005). Total Quality Management. Jakarta: PT. Gramedia Pustaka Utama.

Hudson-Smith,M.,\&Smith,D. (2007). Menerapkan pengukuran kinerja yang selaras secara strategis di perusahaan kecil. Jurnal Internasional Ekonomi Produksi, 106 (2),393.

Hudson, M.,Smart, A., \& Bourne, M. (2001). Teori dan praktek dalam pengukuran kinerja UKM sistem. Jurnal Internasional Operasi dam Manajemen Produksi, 21 (8), 1096-1115.

Notoatmodjo, S. (2003). Pengembangan Sumber Daya Manusia (PT. Rineka Cipta, ed.). Jakarta.

Pearce, J. A., \& Robinson, R. B. (2007). Strategic Management, Formulation, Implementation, and Control. Boston:

Jurnal IImu Sosial dan Humaniora | 299 
McGraw Hill Companies.

Ratnawati, Shinta. (2018). Ekonomi Kreatif dan Kaizen. Jurnal REKOMEN. Anom Pustaka : Yogyakarta.

Sila, I. (2007). Examining the effects of contextualfaktors on TQM and performance through thelens of organizational theory: an empirical study. Journal of Operations Management, 25(1), 83-109.

Simatupang T.M. (2007). Ekonomi Kreatif Berperan Penting. Pikiran Rakyat.

Sugiyono. (2008). Memahami Penelitian Kualitatif. Bandung: CV. ALFABETA.

Suyaman, D. . (2015). Kewirausahaan dan Industri Kreatif. Bandung: ALVABETA.

Van Gils, A. (2005). Manajemen dan Tata Kelola di UKM Belanda.Jurnal Manajemen Eropa,23(5), 583.

Vikaliana Resista. (2016). Model Pembinaan Umkm Industri Kreatif Sebuah Solusi Meningkatkan Daya Saing Global. Prosiding Seminar STIAMI, III(01), 92102.

Wongboonsin, K. \& P. (2003). First and Second Demographic Dividend. Thailand: Chulalongkorn University. 